\title{
OPENING OF THE CENTRE FOR SPINAL INJURIES AND OTHER SEVERELY DISABLED PERSONS AT THE ORTHOPAEDIC CLINIC OF HEIDELBERG UNIVERSITY (GERMANY)
}

\author{
By Dr F. W. MeInecke, Bochum, Germany
}

ON IOth February 1967, many guests of honour from abroad and all parts of Germany assembled to inaugurate together with the patients in their wheel-chairs the clinical department ('Ludwig Guttmann-Haus') and the department for vocational training ('Kurt Lindemann-Haus') of the new Centre for Rehabilitation

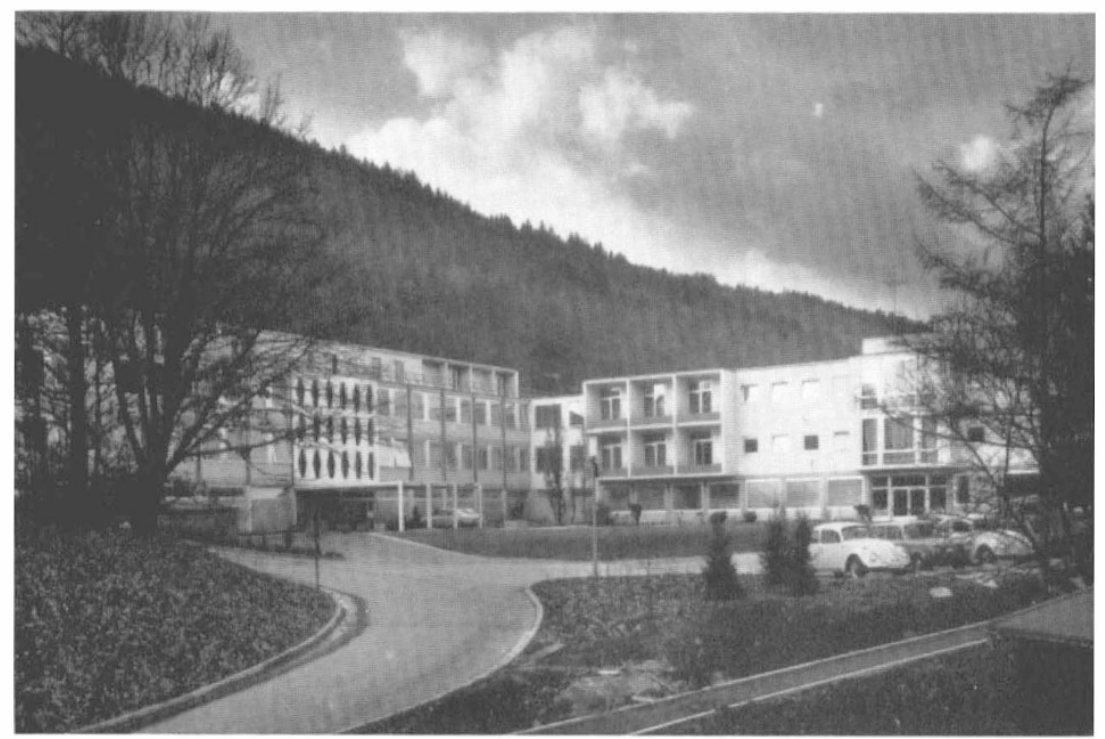

FIG. I

Panoramic view of the Spinal Injuries Centre at the Orthopaedic Clinic of the University, Heidelberg.

of Spinal Injuries and other severely disabled persons of the Orthopaedic Clinic of the University of Heidelberg.

Professor Dr G. Jentschura, commissioned director of the Clinic, remembered with words of deep gratitude the late Professor Dr K. Lindemann who had directed the Clinic until he died on 9th April 1966. The Clinic owes the foundation of this Centre to his unshakable will; neither difficulties nor obstacles could make him give up his plans and abandon his goal to establish a Centre in which paralysed patients could undergo all phases of rehabilitation without a break from the day of their accident until the day of their reintegration into professional life and normal activities. This model unit was not only intended to overcome the stress among these severely disabled persons but also to promote teaching and 


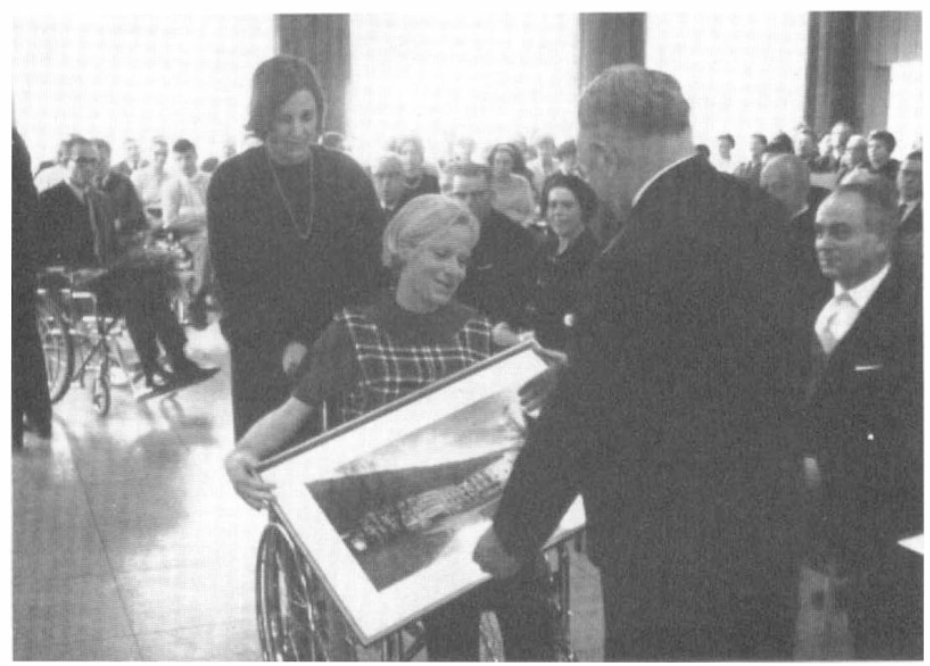

FIG. 2

Sir Ludwig Guttmann receiving a picture of the new Centre from a paraplegic patient.

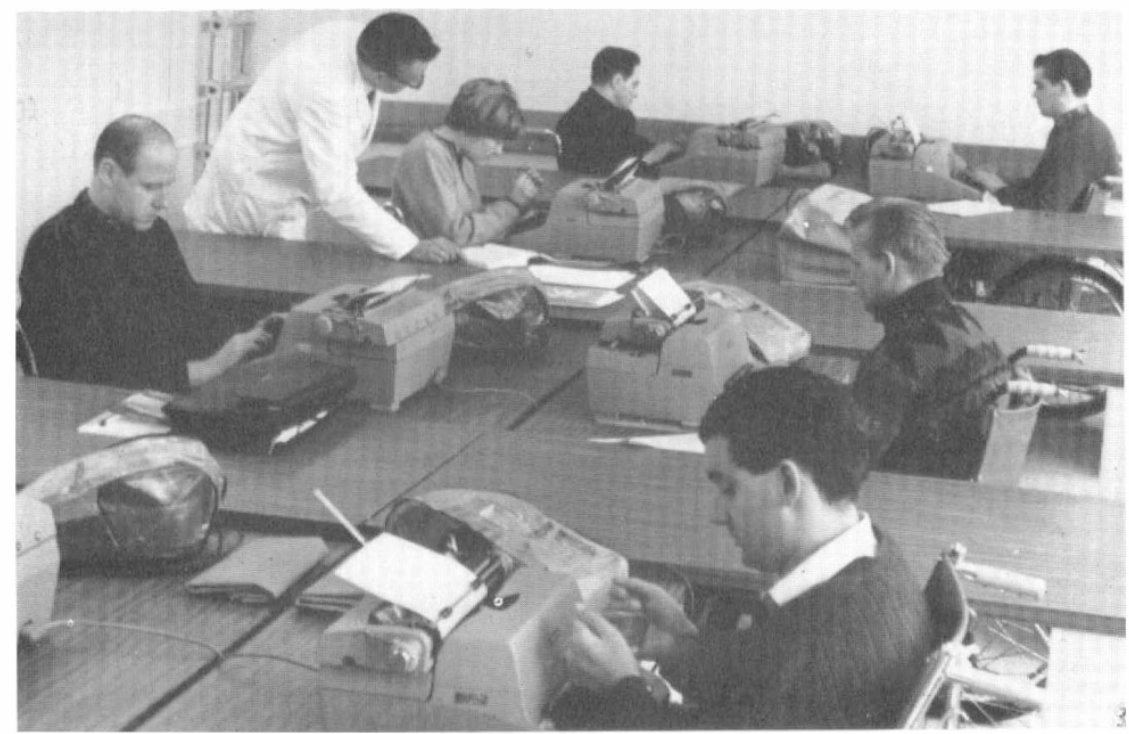

FIG. 3

Department for training in shorthand and typing. Note the technique of typing of the two tetraplegics. 
research work so that new findings and knowledge could be made available to all persons working in this field. With his last work-though he did not live to see its realisation-he erected one of the most remarkable monuments a surgeon or scientist could ever leave behind. But, without the pioneer work done by Sir Ludwig Guttmann, this Centre would have been unimaginable.

Sir Ludwig Guttmann recalled once more the close friendship which had associated him with Lindemann during recent years. He also mentioned that, on the entire European Continent, no other Centre exists providing equally comprehensive possibilities for the whole treatment of spinal cord sufferers within a university. This is indeed the outstanding merit of Lindemann, and it became reality after his visit to Stoke Mandeville, thanks to his far-seeing planning. From all his experience and what he had seen during his journeys to many countries Sir Ludwig considered the Heidelberg Spinal Centre as the most modern and ideal in the whole world. To him personally it was the fulfilment of a dream. The great number of guests who personally addressed the audience indicated how much they approved and supported this Centre and how many hopes and expectations were tied to it. When expressing his thanks to all of them Professor Jentschura especially mentioned Dr Paeslack, director of the unit, who has done a great deal of preparatory work and whose task is now to transcribe Lindemann's conceptions into reality. On his way to achieving this goal our best wishes will accompany him, his co-workers, and his patients.

After a light refreshment the guests were given the opportunity of an inspection tour: 52 in-patients are accommodated in rooms with $3-5$ beds each, Io additional beds for children will be available in the near future. The facilities provide for training in eight different vocations for 56 interns of the boardingschool and 14 out-patients. The training programme includes work test periods, job finding and apprenticeships. Also, all kinds of sports will be carried out. From the day of entering the clinic until they are discharged and re-enter professional life patients take part in remedial exercise and sport, which are an integral part of the rehabilitation programme. Sick-rooms and training rooms are large, light and adequately equipped. The total building costs amounted to I million pound sterling (= IO million DM).

Here, the ties of friendship which so tightly linked Sir Ludwig Guttman and Kurt Lindemann have found their concrete and visible expression. Their names will remain ever-unforgettable to all patients of the unit. 